\title{
The Influence of Climate Variation on Abiotic Plant Stress: A Review
}

\author{
F. G. Ngasoh ${ }^{*}$, E. A. Jandong 2 P. A. Dauda ${ }^{3}$, R. Ismaila ${ }^{4}$ \\ ${ }^{1,3}$ Agricultural and Bioresources Engineering Department, Taraba State University, Jalingo \\ felixngasoh@gamil.com ${ }^{1}$, awhari4047@ gmail.com ${ }^{3}$ \\ ${ }^{2}$ Department of Agronomy, Taraba State University, Jalingo-Nigeria \\ elias.jandong@gmail.com ${ }^{2}$ \\ ${ }^{4}$ Agricultutural and Bio-Environmental Engineering Department, College of Agriculture, Jalingo, Taraba State-Nigeria \\ koyalima04@gmail.com \\ *Corresponding Author
}

\begin{abstract}
The increase in the carbon-dioxide $\left(\mathrm{CO}_{2}\right)$ present in the atmosphere as a result of human activities affects the ambient temperature, and rainfall pattern in terms of season, duration, intensity of sunshine, increased drought periods, waterlogging, and increased evapotranspiration. This influence negatively the development, yield and quality of the plants grown under this condition. The quests to produce stress tolerant/resistant plants and increase crop productivity have led to the study of plant stresses, their response to different stress type and stress management procedures in plants. This paper has discussed in details the different abiotic stressors in plants and how they are being influenced by climate variation, the response of these plants to different abiotic stresses or a combination of stresses, and its management.
\end{abstract}

Keywords-Abiotic Plant Stress, Climate variation, Plant Responses, Stress Management.

\section{INTRODUCTION}

The effects of climate change on the general environment have been very significant over the years, most especially in agricultural plants grown in these environments. According to Intergovernmental Panel on Climate Change (IPCC), stresses are incurred on plants as a result of changes in the climatic conditions of the environment, which has been conclude to be the most influencing factor affecting agricultural production at low lowlands mostly occupied by developing countries[1].It increases the presence of carbon dioxide in the air and also the temperature of the environment[2]. These are major constraints to food supply and balanced environment which has lead most researchers into looking for good adaptation strategies for plantsunder this condition[3], by developing plant species and smart crops that are resilient to the effect of climate change[4]. Vulnerability to this kind of stress inhibited on plants due to climate change results to disruption in the plant metabolism processes, thereby incurring reduction in aptness and quality agricultural crop production[5]. The individual climate change inducing stressors are abiotic in nature [6] and they imposestress on different plant species: these includes drought, elevated $\mathrm{CO}_{2}$, temperature (low and high)[7], waterlogging, rainfall and sunshine intensity, chemical factors (heavy metals and $\mathrm{pH}$ ). The fight against these stress factors are however complex due to the interrelationship amongst them [8], with the major challenge being to understand how these react to different stressors, the diversity response pathways elicited by them and their genetic determination [1, 9, 10].This paper therefore aimed at reviewing the influence of climate variation on abiotic plant stress, responses and management.

\section{Major Abiotic Stressors in Plants}

1.1. Temperature

Development and growth of plants is hinged on the environmental temperature. This varies depending on the crop grown [11]. The effect of temperature on the potentials of plants growth are maximum and minimum daily temperature and variation in the day and night temperature with their respective average temperatures [12]. A significant rise in the temperature due to climate change will over time in reduced rainfall, wind speed and snow cover which will also lead to a reduced length of growing season for plants, and will affect negatively the quality of the crops and agricultural productivity[13]. Fluctuations in the environmental temperature occurs more speedily than 
changes in stress factors thus exasperating the effects of other stresses on plants [8]. The rise in temperature is a result of the global warming which varies regionally. Prospectively, the developing countries are more vulnerable and this may perhaps result in increasing food insecurity in such region. A recent study on the effects of frost and extreme temperatureson wheat production (Triticum aestivum $L$ ) showed that frost caused unfruitfulness and abortion of formed grains while excessive heat resulted in reduction in number of grains formed in filling period of the grain [14]. With the notable effects of these extreme weather events on crop production which results from climate change, the impending effect of climate variation will endanger the production trend of crops thereby giving room for food insecurity. The effect of high temperature stress on a pearl millet, identifying sensitive stages, with parameters like temperature thresholds, genetic variability and fertility of pollen germination being determined. It was found that exposure to high temperature stress reduces pollen germination and seed yield, and also affects the fertility of the pollen and pistil tissues $[15,16]$.

The response of plants to this class of stress depend the type of crop or plant as seen on Fig. 1. Broccoli (Brassica oleracea var. Italica) growth response to temperature started from $5{ }^{0} \mathrm{C}$ and retired at $25{ }^{0} \mathrm{C}$ while that of maize (Zea mays L.) started from approximately $10{ }^{\circ} \mathrm{C}$ and retired at approximately at $40{ }^{0} \mathrm{C}$.

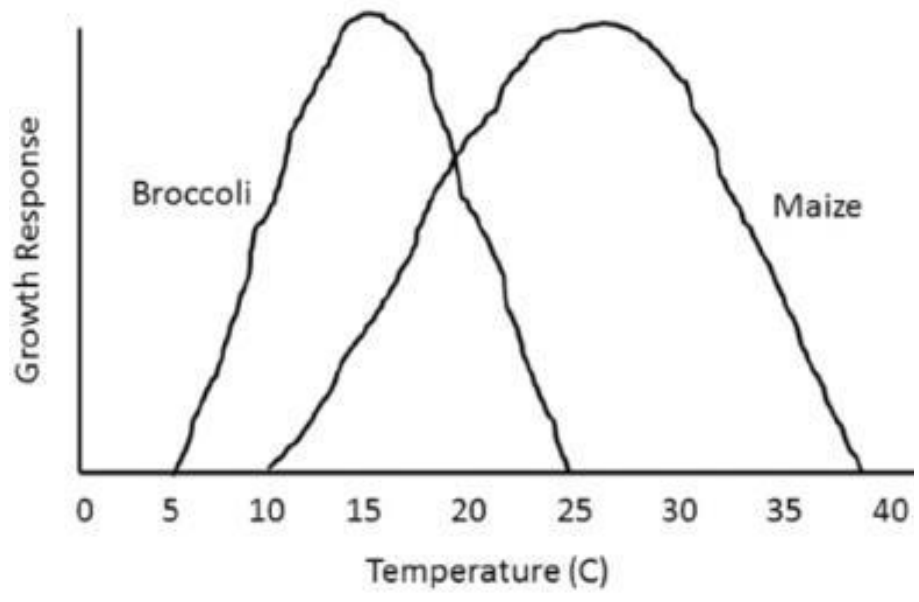

Fig.1: Minimum and Maximum temperature response for maize and broccoli [11]

1.2. Drought and Rainfall pattern

Drought is one of the major abiotic stressor of agricultural plants restraining crops' return globally [17]. It does not only affect the crops growth and yield, also affect the quality of the yield. In an experiment carried out on miscanthus for biofuel production, drought treatment was observed to have declined plant weight by $45 \%$ and the composition of the biomass and cell wall structural rigidity were severely altered due to stress incurred by the plant during the drought period[18]. According to Dhankher (2018), drought as an abiotic stress factor is being projected to hinder productivity in more than $50 \%$ of the arable lands in the world by the next 50 years. But the availability of saline water might lighten the world's water problem if plants that are salt tolerant are being developed[15, 19-22]. However, in response to this kind of plant stress, the need for drought tolerating plant is a necessity to boycott or reduce its negative impacts on food security. Fig. 2 shows an extreme case of drought on a land.

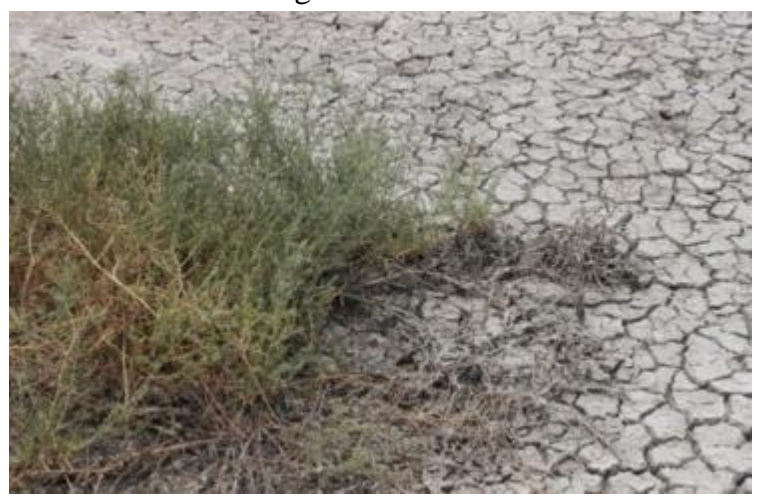

Fig.2: Xerohalophytes growing in soil impacted by severe Drought[15].

Also in terms of rainfall pattern and distribution, already in tropical countries, there is variability in the soil water content as a result of its distribution as reported by [23]. This is an indication that the soil water content is becoming scarce for plants use. In an investigation to know the effect of timing precipitation on grassland and rainforest in USA, the result showed that soil water content available for plant use depend on the amount of precipitation in the study area [24]. That is, when rainfall distribution uniformity is low, the available soil water content would reduce, hence will not uniformly meet the plant's soil-water-nutrient need, thus inducing stress on plants in those affected areas. This is often results from climate change. According to [25] and [26], climate change influences the timing of rainfall from one season or period to the other either resulting in smaller precipitation event or large one depending on the shift. This sudden shift in the precipitation affect plants growths and 
causes plant stress by disturbing plant metabolis m, arresting photosynthesis, and may finally cause plants to die off.

Change in the soil water content and soil features results in having reasonable impact on the plant and soil processes as indicated on by Fig. 3. The response in Above-ground Net Primary Productivity (ANPP) depends on which season receives extra water and which one receives less. The findings here further showed that the soil water content determines the response of Above-ground net Primary Productivity [27]. Generally effects of drought stress on plants includes Reduction in seed germination and development, poor growth in vegetation, poor reproductive growth, reduction in leaf weight, reduced photosynthesis, reduced stomatal conductance andsignificant reduction in the total dry matter.

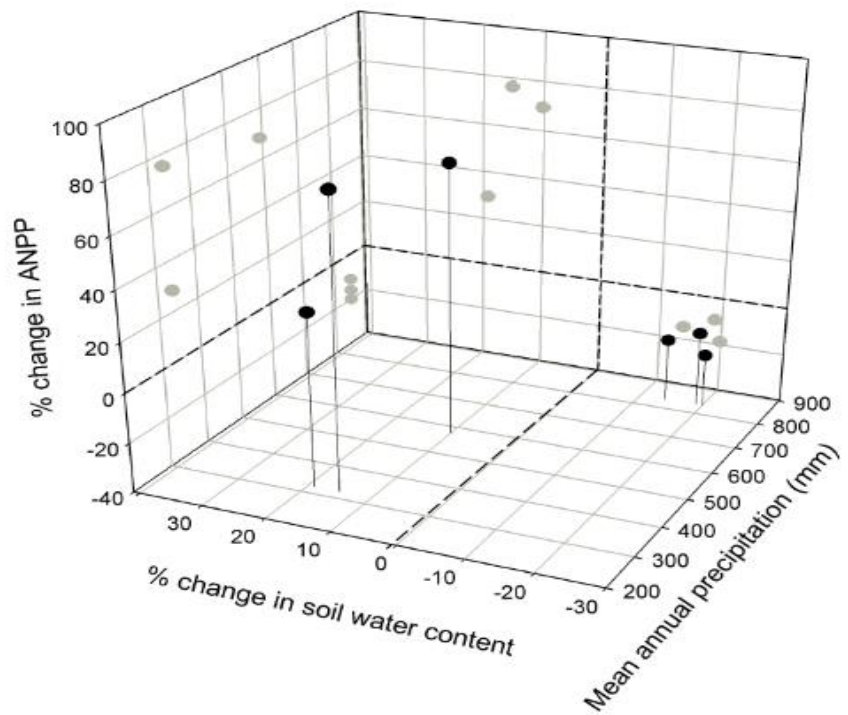

Fig.3: The of effect precipitation at extreme level on the Above-ground Net Primary Productivity through a rainfall slope[18]

1.3. Waterlogging/Flooding
Climate change has altered the hydrological cycle processes which have resulted to impairment or reduction in crop growth in so many areas around the world. Consequently, there is a large scale reduction in agricultural production especially on a flatland or places near the river due to waterlogging [28]. Waterlogging occur as result of leakage from irrigation canals or pure surface drainage but predominantly caused by heavy rainfall in such area [29]. As a result of the built water on the land and soil compaction, the available Oxygen $\left(\mathrm{O}_{2}\right)$ for plants cells are reduced because the diffusion process of $\mathrm{O}_{2}$ is slow in ponding water $[29,30]$. Due to the limited supply in $\mathrm{O}_{2}$, anaerobic bacteria releases venomous amount of Iron ion, Manganese ion and sulphide [29].

Crops grown in a waterlogged condition undergo different physiological and morphological variations [29]. One of the major response of plant to waterlogging stress is stomatal cessation which impacts not only gas exchange, but also reduces the submissive absorption of $\mathrm{H}_{2} \mathrm{O}$, which is harmfully prejudiced by anaerobic conditions in the rhizosphere [28]. Transpiration is also reduced which eventually results to wilting of the leaf and early senescence; consequentially, foliar abscission will become the result [31]. In flood logged area, respiration of roots are not aerated in which gas diffusion are severely reserved, thereby resulting to it changing from aerobic to anaerobic conditions which is dangerous to plants development [31, 32]. Waterlogging also deters the nutrients intake of plants as presented in Table 1. [33] in an investigation to know the effect of waterlogging on growth nutrient concentrations observed that there was high sprout dry weight of wheat in the waterlogged treatments compared to the control. Both in barley and wheat there was an indication of reduction nutrient such as Nitrogen, Phosphorus, Potassium, Manganese, Copper, Zinc and Magnesium as shown on Table 1.

Table 1: Mineral concentrations of spring barley and spring wheat shoots as related to a 15 days period of waterlogging

\begin{tabular}{|c|c|c|c|c|c|c|}
\hline & \multicolumn{3}{|c|}{ Wheat } & \multicolumn{3}{|c|}{ Barley } \\
\hline Nutrients & Control & Waterlogged & $\mathrm{SC}$ & Control & Waterlogged & $\mathrm{SC}$ \\
\hline \multicolumn{7}{|c|}{$\mathrm{Mg} / \mathrm{g}$ dry matter } \\
\hline $\mathrm{N}$ & 47.1 & 38.1 & $30-45$ & 49.9 & 34.8 & $20-40$ \\
\hline $\mathrm{P}$ & 6.2 & 4.9 & $3.5-6.0$ & 5.1 & 3.9 & $3.5-6.0$ \\
\hline K & 57.4 & 48.6 & $33-45$ & 63.2 & 45.1 & $30-55$ \\
\hline $\mathrm{Ca}$ & 6.3 & 5.8 & $4-10$ & 8.3 & 6.9 & $5-10$ \\
\hline $\mathrm{Mg}$ & 1.9 & 1.4 & $2-3.5$ & 2.3 & 1.9 & $1.5-3.0$ \\
\hline
\end{tabular}




\begin{tabular}{ccccccc}
$\mathrm{Mn}$ & 41.8 & 27.5 & $35-100$ & 37.9 & 21.9 & $30-100$ \\
$\mathrm{Cu}$ & 12.2 & 10.0 & $7-15$ & 10.5 & 7.2 & $6-12$ \\
$\mathrm{Fe}$ & 92.8 & 89.7 & - & 89.9 & 69.1 & - \\
$\mathrm{Zn}$ & 39.6 & 28.5 & $25-70$ & 38.4 & 26.5 & $20-60$ \\
\hline $\mathrm{Mg} / \mathrm{g}$ dry matter & & & & & & \\
$\mathrm{N}$ & 49.1 & 29.0 & $30-45$ & 48.9 & 34.5 & $20-40$ \\
$\mathrm{P}$ & 4.6 & 3.3 & $3.5-6$ & 4.4 & 3.6 & $3.5-6.0$ \\
$\mathrm{~K}$ & 50.5 & 28.0 & $33-45$ & 54.5 & 28.1 & $30-55$ \\
$\mathrm{Ca}$ & 4.9 & 6.2 & $4-10$ & 8.1 & 12.2 & $5-10$ \\
$\mathrm{Mg}$ & 3.2 & 2.0 & $2-3.5$ & 3.0 & 2.8 & $1.5-3.0$ \\
\hline $\mathrm{Mg} / \mathrm{kg}$ dry matter & & & & & \\
$\mathrm{Mn}$ & 53.9 & 35.1 & $35-100$ & 63.9 & 47.7 & $30-100$ \\
$\mathrm{Cu}$ & 10.7 & 7.9 & $7-15$ & 10.1 & 9.4 & $6-12$ \\
$\mathrm{Fe}$ & 72.1 & 70.0 & - & 69.5 & 71.0 & - \\
$\mathrm{Zn}$ & 38.6 & 21.4 & $25-70$ & 40.5 & 34.1 & $20-60$ \\
\hline \multicolumn{7}{r}{} \\
\hline
\end{tabular}

Source: Adopted from [33]

\subsection{Salinity}

The effect of salinity on agricultural crop production and food supply according to [15] has been on the increase worldwide, with the cultivation of salt-sensitive crops such as rice and wheat being a worldwide practice [34], salinity stress needs to be promptly addressed. Rice according to [34] is one of the crops planted most around the world as it is a major source of food for almost all humanity. Thirtynine (39) million hectares out of the 130 million hectares of land on which rice is cultivated worldwide contains a certain degree of salinity which varies with the rice cultivar $[35,36]$. Salinity is a stressor common to arid and semi-arid regions of the world where evapotranspiration exceeds rainfall, and as a resultleads to inadequate rain to filter away the soluble salts from the root zone[37]. Lands with salinity stress problem covered at least 7 percent of the world land area four decades ago according to [37], and has been seen to double every two decades. Showing that the salinity stress problem is rapidly increasing every day majorly as a result of climate change[38, 39]. Approximately 1.6 Mha of land is being lost to salinity stress every year, with 60 percent salinization coming from natural sources (weathering of minerals, and soils developed from saline rocks) and 40 percent coming from secondary sources(irrigation, deforestation, overgrazing or intensive cropping). But ironically majority of the land loss as a result of secondary salinization is caused as an adverse effect of irrigation of the farmland[37] with both normal water and treated sewage effluents. This takes place in at least 20 percent of irrigated lands in agriculture [38]. The salinity stressor reduces drastically the ability of plants to take up water and other nutrients from the soil, leading to stunted growth; salt deposits find their way into the transpiration stream and damage the cells in leaves thereby causing leaf burn; it also affects the enzyme activity happening within the plant.The salinity of a soil is measured in terms of electrical conductivity (EC), and these soils have a mixture of salts of Sulfate, Sodium, Magnesium, Chlorine and Calcium

But most often, it is the combination of two more stressor that sometimes affect growth of a plant, for example heat and salinity or drought and heat as indicated by the Venn diagram presented in Fig. 1 [6]. Several researches have investigated the combine effects of drought and heat stress on maize, sorghum and turf-grasses growth and productivity. The studies showed that the combine effects of the two stressors were higher compared to when the stresses were applied individually [40-42].
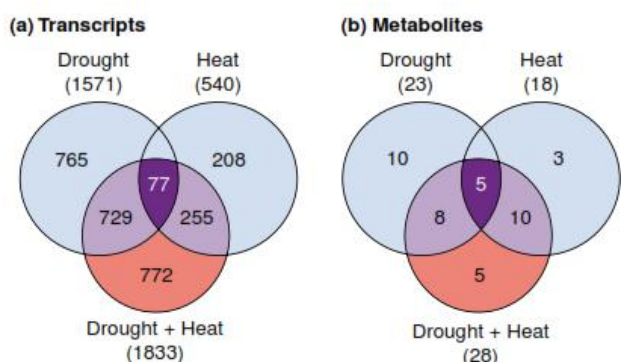

Fig.4: Unique molecular characteristics of drought and heat stress combination [6] 


\section{PLANT RESPONSES TO ABIOTIC STRESS}

Having seen that abiotic stresses on plants like temperature, flooding, drought, and salinity affect crop production heavily, as they cause stunted growth in plants, affects plant metabolism and thus reducing crop yield by as much as $70 \%$ [43], it has also been seen that $50 \%$ of crop yield losses come as a result of abiotic stress in most crop plants [43]. Also with the constant changes in the climatic conditions of the world, most of these abiotic stresses on plants are made worse than how it was in previous years. For example the increased presence of $\mathrm{CO}_{2}$, methane, Nitrous oxide and Chloro-flourocarbons in the atmosphere as a result of industrialization and other human activities have increased drastically the average ambient temperature which causes heat stress $[43,44]$. This increase in the ambient temperature of the environment also increases the evaporation in water bodies, thereby causing an unexpected decrease in the available water for crop production which in extreme cases leads to drought $[4,34,43]$. Therefore a better understanding of plant responses to these abiotic stresses and their tolerance mechanism will help improve crop resistance and productivity [45, 46].

Plants response to Abiotic stresses depends heavily on their developmental stage. Their response to drought and flooding according to [43] is majorly ordered by genetic expression and biochemical metabolism via different physiological processes. Some of the morphological growth indices affected by drought stress is the leaf area of the plant, the plant height, dry matter and biomass production. The photosynthetic efficiency, gas exchange measurements, the stomatal conductance, the phytochemical and the nonphytochemical quenching, malondi-aldehyde (MDA) and relative water content are the physiological indices put in check during the evaluation of drought stress in plants [47]. Therefore plants undergoing this type of stress gradually losses water from the protoplasm, the plant cell will dehydrates and this affects the structure of the plant cell [43, $45,48]$. When all the free water in the protoplasm of the plant cell is lost, only plants that are dessication-tolerant (resurrection plants) will remain, and others will die off [43].

Plant's architecture is altered during flooding, although this is majorly dependent on the type of flood. When the plants are covered completely with floodwater, plant growth is stopped to conserve energy to be used once the level of water goes down. This strategy is important when the plant is completely flooded[43, 45]. In situations whereby the plantsare completely flooded for a long period of time, the plant dies off as a result of the food reserve being completely depleted. During this period, there is also low oxygen $\left(\mathrm{O}_{2}\right)$, and the plants resort to rearranging their anatomy and metabolism so they can be able to function. This rearrangement to create space and a continuous gas channel to facilitate an internal $\mathrm{O}_{2}$ from the canopy to the root of the plant is known as aeranchyma [45]. Adjustment to the metabolic pattern of the plants during flood stress is driven by hormones like the abscisic acid, gibberlin, and ethylene.

In periods of high temperature, there is a very severe damage to the chlorophyll, as heat stress changes the structural arrangement of the thylakoids, thus affecting its functionality, and also reduces the chlorophyll content of the plant. The above adverse effects on the plant reduces the ability of the plant to photosynthesize because by reducing the chlorophyll content, the photosynthetic pigments are reduced, thereby leading to physiological impairment and reduced growth of the plant [49]. The leaf of the plant also loses water under high temperatures thus leading to stomatal closure due to reduced leaf water potential[43, 49]. According to [50] stomatal closure is the major factor affecting photosynthesis in plants. High temperatures according to [51] causes impaired pollen and ovary development which adversely leads to the bad reproductive health of plants. Plants also undergo denaturation of protein and enzymes under extreme temperature conditions which gives rise to the programmed death of the tissues and cells $[43,52]$.

\section{ABIOTIC STRESS MANAGEMENT}

Managing abiotic stresses in plants is a very is a challenging task because of its multifaceted nature. Comprehensive researches for the development of abiotic stress tolerance in plants are in progress, comprising genes from several pathways like the osmolyte synthesis, ion homeostasis, antioxidative pathways, and regulatory genes [53]. Several attempts have been made to substantiate the role of "singlefunction" gene(s) in the past ten (10) as well as transcription factor(s) for abiotic stress tolerance [53]. Because abiotic stress tolerance is multigenic in nature, the modern trend is moving towards genetic transformation of multiple genes or transcription factors. Generally, abiotic stresses can be managed by genetically improving the genes and transcription factors, or by employing cultural practices which includes modification and adjustment of planting time and crop density in the field so as to contain the effect of these abiotic stresses. Another method is to apply phyto- 
hormones, signaling and trace elements and also by applying osmo-protectants [44, 51].

Conventionally, some of the plants tolerant to these abiotic stresses discussed in the previous sections can be recognized when proper screening methods and criteria for selection are employed via cultural field breeding techniques, like modifying planting time and adjusting the compactness of plants cultivated to evade these stress situations [43, 52]. One major limitation in adopting the conventional field screening of these plants is that the screening and identification process of a plant for a particular type of stress-tolerant trait might be severely influenced by other stress factors. For instance, the quality of the screening process of a plant for cultivars tolerant to extreme temperature stresses, might be affected by other stresses either biotic (pests and pathogens) or abiotic (salinity). Therefore $[44,52]$ was of the opinion that glasshouses screening should be employed as an alternative to field screening [43]. Selection of some stress-tolerant plants for cultivation has been has notably been hindered by the polygenic nature of the trait, epistasis, genotype by environment and low heritability[43]. These traits can be identified by carrying out Quality trait Loci (QTL) analysis . The Qualitative trait Loci (QTL) analysis according to [43, $44,52]$ were carried out on rice, maize and wheat and heat stress tolerant traits were found. Although these traits were found to be associated with the reproductive stage of these plants [43, 54, 55]. Some other Loci, like the Loci for freezing tolerance at vegetative stage, chilling at seedling stage, submergence-tolerance Loci was also found in Arabidopsis model plants, maize and rice.

Biotechnological advancement has of recent given way to genetically modify the crop plants to be resistant or tolerant to some stress factors [56]. Advancement in biotechnology and genetic engineering brought out tools and methods of controlling the mechanism of abiotic stress resistance, and for developing crops tolerant to specific stress by introgression of the genes involved in stress response and putative tolerance [57]. This is important as it introduces the modified genes into genomes of elite breeding lines, and as such helps to improve crop varieties $[16,52,54,56,57]$

\section{CONCLUSION}

It can be seen that climate change severely intensifies the effect of these abiotic stresses on plants. The stresses not properly managed makes it impossible to meet global food demand. The tolerance of plants to abiotic stress is as a result of activities ofdiverse stress-responsive genes that relate with other elements of stress-transducing pathways. A very good knowledge of the physiological processes in response to different abiotic stress will help design methods and mechanisms to transform in order to improve tolerance of different abiotic stress in plants. Thus, stress-tolerant gene resources from crop plants, model plants and microorganisms need to be identified and developed by making use of appropriate genetic transformation technologies.

\section{REFERENCES}

[1] P. Andy, "Abiotic Stress Tolerance in Plants," Plant Science, vol. 7, pp. 1-9, 2016.

[2] T. Hirayama and K. Shinozaki. (2010, Research on plant abiotic stress responses in the post-genome era: past, present and future. The plant journal61, 1041-1052.

[3] C. Rosenzweig, J. Elliott, D. Deryng, "Assessing agricultural risks of climate change in the 21st century in a global gridded crop model intercomparison," in Proceedings of National Academic Science U.S.A, 2014, pp. 3268-3273.

[4] T. Wheeler and J. Von Braun, "Climate change impacts on global food security," Science direct, vol. 341, pp. 508-513, 2013.

[5] I. B. Rejeb, V. Pastor, and B. Mauch-Mani. (2014, Plant Responses to Simultaneous Biotic and Abiotic Stress: Molecular Mechanisms Plant, Cell \& Environment [Review]. 3, 458-475.

[6] R. Mittler. (2006, Abiotic stress, the field environment and stress combination. TRENDS in plant Science11(1), 15-19.

[7] S. Compant, M. G. Van Der Heijden, and A. Sessitsch. (2010, Climate change effects on beneficial plantmicroorganism interactions. FEMS microbiology ecology73(2), 197-214.

[8] M. Ashraf and M. R. Foolad. (2005, Roles of gly cine betaine and proline in Improving plant abiotic stress resistance. Environmental and Experimental Botany59, 206-216.

[9] C. Bellard, C. Bertelsmeier, P. Leadley, "Impacts of climate change on the future of biodiversity," Ecological Letters, vol. 15,2012

[10] J. S. Wallace, M. C. Acreman, and C. A. Sullivan, "The sharing of water between society and ecosystems: from conflict to catchment-based co-management," in Philos. Trans. R. Soc. Lond. B: Biol. Sci., London, 2003, pp. 20112026.

[11] J. L. Hatfield and J. H. Prueger. (2015, 13/10/2018). Temperature extremes: Effect on plant growth and development. Weather and climate extremes 10, 4-10.

[12] U. Essay. (2013, 13th October). Effect of temrature on plant growth. Available: https://www.ukessay s.com/essay s/environmentalsciences/effect-temperatures-plant-growth-8273.php?vref=1 
[13] A. A. Naglaa, V. Moses, and C. S. Prakash, "Climate Change effects on Abiotic Stress in Plants," GM Crop Food, vol. 5, pp. 77-80, 2014.

[14] K. Barlow, B. Christy, G. O'leary, "Simulating the impact of extreme heat and frost events on wheat crop production: a review," Field Crops Research, vol. 171, pp. 109-119, 2015.

[15] A. Dhankher, Climate resilient crops for improving global food security and safety vol. 2018: John Wiley and Sons Ltd, 2018.

[16] M. Djanaguiraman, R. Perumal, I. A. Ciampitti, "Quantifying pearl millet response to high temperature stress: thresholds, sensitive stages, genetic variability and relative sensitivity of pollen and pistil," Plant, Cell and Environment, vol. 41, pp. 993-1007, 2017.

[17] R. Tuberosa, S. Grillo, and R. P. Ellis, "Unravelling the Genetic Basis of Drought Tolerance in Crops," in Abiotic Plant stresses, L. S. d. Toppi and B. Pawlik-Skowronska, Eds., ed: Springer, Dordrecht, 2003.

[18] T. Van-Der-Weijde, L. M. HUXLEY, S. HAWKINS. (2017, Impact of drought stress on growth and quality of miscanthus for biofuel production. GCB Bioenergy9, 770782.

[19] T. C. Kerr, H. Abdel-Mageed, L. Aleman, "Ectopic expression of two AREB/ABF orthologs increases drought tolerance in cotton (Gossypium hirsutum)," Plant, Cell and Environment, vol. 41, pp. 898-907, 2017.

[20] N. Lakra, C. Kaur, K. Anwar, "Proteomics of contrasting rice genotypes: Identification of potential targets for raising crops for saline environment," Plant, Cell and Environment, vol. 41, pp. 947-969, 2017.

[21] M. Herzog, D. Konnerup, O. Pedersen, "Leaf gas films contribute to rice (Oryza sativa) submergence tolerance during saline floods," Plant, Cell and Environment, vol. 41, pp. 885-897, 2017.

[22] M. Pérez-Jiménez, M. Hernández-Munuera, M. C. Piñero, "Are commercial sweet cherry rootstocks adapted to climate change? Short-term waterlogging and Carbon dioxide effects on sweet cherry " Plant, Cell and Environment, vol. 41, pp. 908-918, 2017.

[23] M. D. Smith, "An ecological perspective on extreme climatic events: a synthetic definition and framework to guide future research," Journal of Ecology, vol. 99, pp. 656-663, 2011.

[24] M. J. B. Zeppel, J. V. Wilks, and J. D. Lewis. (2013, Impacts of extreme precipitation and seasonal changes in precipitation on plants. Biogeosciences 11, 3083-3093.

[25] IPCC, "Summary for Policymakers " in Intergovernmental Panel on Climate Change Special Report on Managing the Risks of Extreme Events and Disasters to Advance Climate Change Adaptation, C. B. Field, et al., Eds., ed. Cambridge, UK and New York, NY, USA: Cambridge University Press, 2011.

[26] A. J. Pitman and S. E. Perkins. (2008, Regional projections of future seasonal and annual changes in rainfall and temperature over Australia based on skill-selected AR(4) models. Earth Interact12, 1-15.

[27] J. L. Heisler-White, J. M. Blair, E. F. Kelly, "Contingent productivity responses to more extreme rainfall regimes across a grassland biome," Glob. Change Biol., vol. 15, pp. 2894-2904, 2009.

[28] F. Aldana, P. N. García, and G. Fischer, "Effect of waterlogging stress on the growth, development and symptomatology of cape gooseberry (Physalis peruviana L.) plants," Rev. Acad. colombia Ciene, vol. 38, pp. 393-400, 2014.

[29] M. Ashraf and S. Mehmood, "Effects of waterlogging on growth and some physiological parameters of four Brassica " Plant and soil, vol. 121, pp. 203-209, 1990.

[30] L. Taiz and E. Zeiger, Plant physiology, 5th ed. Sunderland, MA: Sinauer Association Inc., , 2010.

[31] M. A. Ashraf, "Waterlogging stress in plants: A review," African Journal of Agricultural Research, vol. 7, pp. 19761981, 2012.

[32] R. Akula and G. A. Ravishankar, "Influence of abiotic stress signals on secondary metabolites in plants," Plant signaling \& behavior, vol. 6, pp. 1720-1731, 2011.

[33] D. Steffens, B. W. Hütsch, T. Eschholz, "ater logging may inhibit plant growth primarily by nutrient deficiency rather than nutrient toxicity," Plant soil Environment, vol. 15, pp. 545-552, 2005.

[34] Food and Agricultural Organisation of the United Nations, "The future of food and agricultural trends and challenges," food and Agricultural Organisation, Rome2015.

[35] W. Wang, B. Vinocur, and A. Altman, "Plant response to drought, salinity, and extreme temperatures: Towards genetic engineering for stress tolerance," Planta, vol. 218, pp. 1-14, 2003.

[36] B. Vinocur and A. Altman, "Recent advances in engineering plant tolerance to abiotic stress: Achievements and limitations. ," Current opinion in Plant science, vol. 16, pp. 1-10, 2005.

[37] D. Vijayalakshmi, "Abiotic Stresses And Its Management In Agriculture," in Stresses in Plants, ed India: Springer, 1999.

[38] T. J. Flowers and A. R. Yeo, "Breeding for salinity resistance in crop plants-Where next," Australian Journal of Plant Physiology, vol. 22, pp. 875-884, 1995.

[39] F. Massoud, "Salinity and alkalinity as soil degradation hazards.," Food and Agricultural Organisation, Rome1998.

[40] P. Q. Craufurd and J. M. Peacock, "Effects of heat and drought stress in Sorghum," Exp. Agriculture, vol. 29, pp. 77-86, 1993.

[41] Y. Jiang and B. Huang, "Drought and heat stress injury to two cool season turfgrasses in relation to antioxidant metabolism and lipid peroxidation," crop science, vol. 41, pp. 436-442, 2001 
[42] Z. L. Wang and B. R. Huang, "Physiological recovery of Kentucky bluegrass from simultaneous drought and heat stress.," Crop science, vol. 44, pp. 1729-1736, 2004.

[43] K. S. Arun-Chinnappa, L. Ranawake, and S. Seneweera, "Impacts and Management of Temperature and Water Stress in Crop Plants," in Abiotic Stress Management for Resilient Agriculture, P. S. Minhas, Ed., ed Australia: Springer, 2017, pp. 221-233.

[44] A. Wahid, S. Gelani, M. Ashraf, "Heat tolerance in plants; An Overview," Environmental Exp. Bot, vol. 61, pp. 199223, 2007.

[45] E. A. Bray, J. Bailey-Serres, and L. A. C. J. Voesenek, Response of plants to Abiotic Stresses. Rockville: American society of Plant physiologists, 2000.

[46] N. Fernando, S. Mnailil, S. Florentine, "Glyphosate resistance of $\mathrm{C} 3$ and $\mathrm{C} 4$ weeds under rising atmospheric CO2," Front Plant Science, vol. 7, p. 910, 2016.

[47] M. A. Jenks and P. M. Hasegawa. (2005). Plant Abiotic Stress. 1.

[48] I. B. Rejeb, V. Pastor, and Mauch-Mani, "Plant Responses to Simulteneous Biotic and Abiotic Stress: Molecular Mechanisms," Plants, vol. 2014, pp. 458-475, 2014.

[49] Z. Xu, G. Zhou, and H. Shimizu, "Plant responses to drought and rewatering," Plant signal behaviour, vol. 5, pp. 649-654, 2010.

[50] D. H. Greer and M. M. Weedon, "Modelling photosynthesis response to temperature of grape vine (vitus vinifera ev. Semillon) leaves on vines grown in a hot climate.," Plant Cell and Environment, vol. 35, pp. 1050-1064, 2012.

[51] M. Hassanuzzaman, M. A. Hossain, and M. Fujita, "Physiological and biochemical mechanisms of nitric oxide induced abiotic stress tolerance in plants.," American Journal of Plant Physiology, vol. 5, pp. 294-324, 2010.

[52] M. Hassanuzzaman, K. Nahar, and M. Fujita, Extreme Temperature responses, Oxidative stress and antioxidant defense in plants: IntechOpen, 2013.

[53] P. K. Agarwal, P. S. Shukla, S. K. Gupta, "Genetic Engineering of plant genes," Molecular Biotechnology, vol. 54, pp. 103-123, 2013.

[54] N. C. Collins, F. Tardieu, and R. Tuberosa, "Quantitative trait Loci and crop performance under abiotic stree; where do we stand?," Plant Physiology, vol. 147, pp. 469-486, 2008.

[55] S. Talukder, M. Babar, K. Vijayalakshmi, "Mapping Qualitative Trait Loci for the traits associated with heat tolerance in wheat," BMC genetics, vol. 15, p. 97, 2014.

[56] M. Hassanuzzaman, K. Nahar, M. G. M. Alam, "Physiological, Biochemical and Molecular Mechanisms of heat stress tolerance in plants," International Journal of Molecular Science, vol. 14, pp. 9643-9684, 2013.

[57] P. Bhatnaga-Mathur, V. Vadez, and K. K. Sharma, "Genetic Modifications for stress tolerants in plants," Plant Cell repository, vol. 27, pp. 411-424, 2007. 